\title{
Inguinal ovary in adult women-case report and literature review
}

\author{
Mette L Josefsson ${ }^{1 *}$, Surajit Mitra ${ }^{1}$ and Sanjay Gupta ${ }^{2}$
}

\begin{abstract}
This paper describes a rare finding of an inguinal ovary in an adult woman who presented with pelvic pain. Inguinal ovary may occur if the gubernaculum fails to attach to the uterus or if the canal of Nuck remains open during fetal development.
\end{abstract}

\section{Introduction}

Ovary within the inguinal canal is occasionally seen in infants, but is rare in adult women. This paper describes a woman with an inguinal ovary who presented with pelvic pain. We review the literature and discuss its embryological background.

\section{Case report}

A 33 year-old-woman presented with pelvic pain on a background of longstanding left sided iliac fossa pain, which was exaggerated by constipation and movement. Past medical history included depression, scarred left kidney from recurrent urinary tract infections and surgery for urethral diverticulum. Obstetric history included two vaginal deliveries following subfertility treatment. Ultrasound scan demonstrated an unremarkable retroverted uterus and normal renal tract. The right ovary appeared normal however left ovary was not identified. Diagnostic laparoscopy revealed the left ovary herniating through the left internal inguinal ring (Figure 1a-b). The left ovarian and round ligaments were absent and only a small left fallopian tube was seen (Additional file 1: Figure S1). Uterus, and right tube, ovary and round ligament appeared normal. She later underwent laparoscopic mobilization of the ovary and mesh repair of the inguinal canal jointly with the general surgeons (Additional file 2: Figure S2). She recovered well and was discharged home two days later.

\footnotetext{
* Correspondence: m.josefsson@doctors.org.uk

'Department of Obstetrics and Gynaecology, Lister Hospital, Coreys Mill Lane, Stevenage, Hertfordshire SG1 4AB, UK

Full list of author information is available at the end of the article
}

\section{Comment}

A literature search revealed twelve case reports in adults. The majority presented with a palpable groin mass and they were diagnosed at time of surgery for suspected bowel hernia (Tagliaabue 2011; Machado \& Machado 2011; Mandel et al. 2010; Alzaraa 2011). One woman presented with pelvic pain and was found on laparoscopy to have a rudimentary uterine horn and ovary herniating through the inguinal canal (Al Omari et al. 2011). Coexisting mullerian and renal malformations have been described (Alzaraa 2011; Al Omari et al. 2011).

Male and female reproductive systems share common steps in early development. Understanding this helps to comprehend the causes of inguinal ovary. The gonads develop from mesothelium on the urogenital ridge. Initially in both male and female, the gonads are situated posterior in the abdominal cavity. After sex differentiation both ovaries and testes descend, but to varying extent. The testes descend to the scrotum via the gubernaculums, a caudal remnant of the mesonephric duct that passes through the abdominal wall to the labioscrotal swelling. As the embryo grows the gubernaculums remains the same size causing the testes to be situated progressively lower down. By the eight month the testes have reached the scrotum and by birth the processus vaginalis at the internal inguinal ring closes.

Contrary to the testes, the ovary descends to a lesser extent because the gubernaculums adheres to the uterus, thus preventing movement. If the gubernaculum fails to attach, the ovary may descend through the inguinal canal. The canal of Nuck is a pouch of peritoneum, analogous to the processus vaginalis in males, which follows the round ligament from the ovary to the labia via the inguinal canal. 

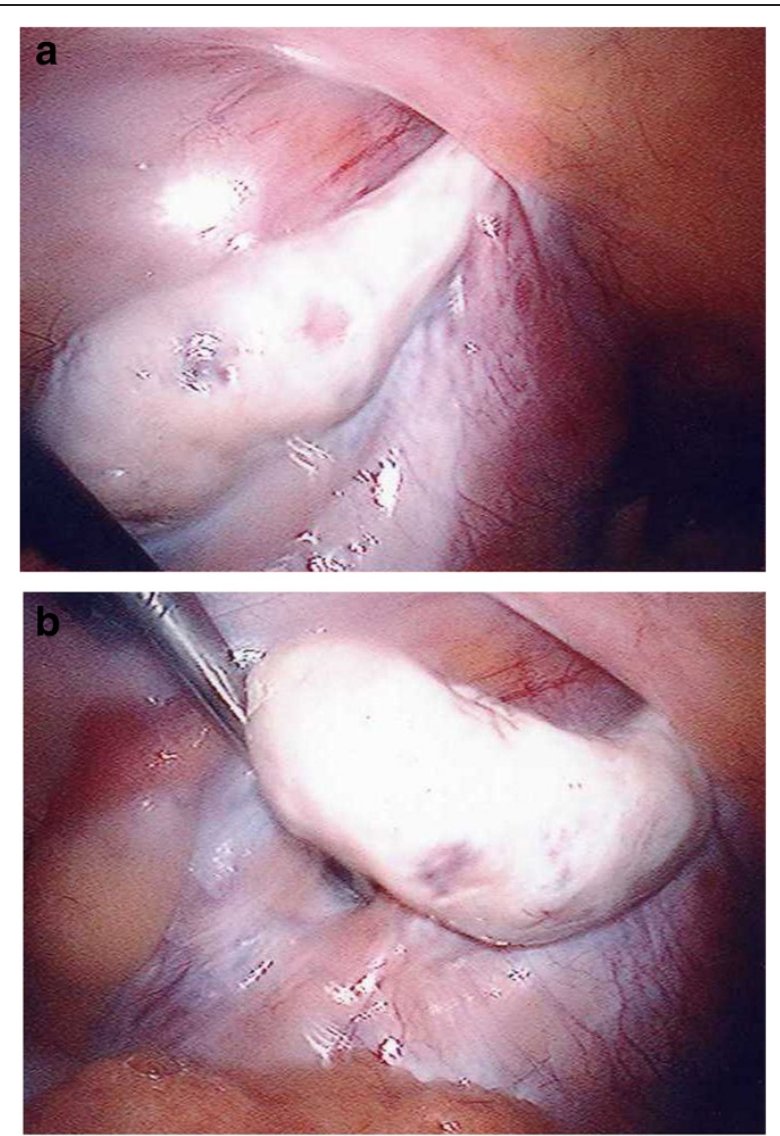

Figure $1 \mathrm{a}$ and $\mathrm{b}$, Laparoscopic images of left ovary herniating through the left internal inguinal ring.

This canal closes within the first year of life. If it fails to close a hernia may form.

\section{Conclusion}

This paper describes a rare case of inguinal ovary in a woman who presented with pelvic pain. An inguinal ovary may occur if the gubernaculum fails to attach to the uterus in fetal life or if the canal of Nuck remains open after birth.

\section{Consent}

Written informed consent was obtained from the patient for publication of this case report and accompanying images. A copy of the written consent is available for review by the Editor-in-Chief of this journal.

\section{Additional files}

Additional file 1: Figure S1. Laparoscopic image of uterus and right ovary. Note the absence of left ovary, left ovarian ligament and left fallopian tube.

Additional file 2: Figure S2. Laparoscopic image of left ovary following its removal from the inguinal canal and mesh repair of the hernia.

\section{Competing interests}

Mette Josefsson, Surajit Mitra, and Sanjay Gupta declare that they have no conflict of interest.

\section{Authors' contributions}

Patient was under the care of SM. The idea and planning was done by SM. SG did the mesh repair. MLJ did the literature search and writing of the draft. All authors contributed to revising the paper. All authors read and approved the final manuscript.

\section{Acknowledgement}

We acknowledge the patient who the case report is based on. The patient did not receive any financial compensation.

\section{Author details}

'Department of Obstetrics and Gynaecology, Lister Hospital, Coreys Mill Lane, Stevenage, Hertfordshire SG1 4AB, UK. ²Department of General Surgery, Lister Hospital, Coreys Mill Lane, Stevenage, Hertfordshire SG1 4AB, UK.

Received: 23 September 2013 Accepted: 7 October 2013 Published: 17 October 2013

\section{References}

Al Omari W, Hashimi H, Al Bassam MK (2011) Inguinal uterus, fallopian tube, and ovary associated with adult Mayer-Rokitansky-Kuster-Hauser syndrome. Fertil steril 95:1119

Alzaraa A (2011) Unusual contents of the femoral hernia. Obstet gynaecol 2011:717924

Machado NO, Machado NN (2011) Unusual contents of inguinal hernia sac. An approach to management. Surg Sci 2:322-325

Mandel DC, Beste T, Hope W (2010) Hernia uterine inguinale: an uncommon cause of pelvic pain in the adult female patient. J mimim invas gyn 17:787-790

Tagliaabue F (2011) Indirect inguinal hernia containing fallopian tube, ovary and ovarian cyst in adult woman. Chirurigia 24:95-97

doi:10.1186/2193-1801-2-545

Cite this article as: Josefsson et al:: Inguinal ovary in adult women-case report and literature review. SpringerPlus 2013 2:545.

\section{Submit your manuscript to a SpringerOpen ${ }^{\odot}$ journal and benefit from:}

- Convenient online submission

- Rigorous peer review

- Immediate publication on acceptance

- Open access: articles freely available online

- High visibility within the field

- Retaining the copyright to your article

Submit your next manuscript at springeropen.com 